\title{
METHODS OF ASSESSMENT AND TRAINING OF A COMPANY TOWARDS THE ENTERPRISE 4.0
}

\author{
Baicu Andrei Valentin
}
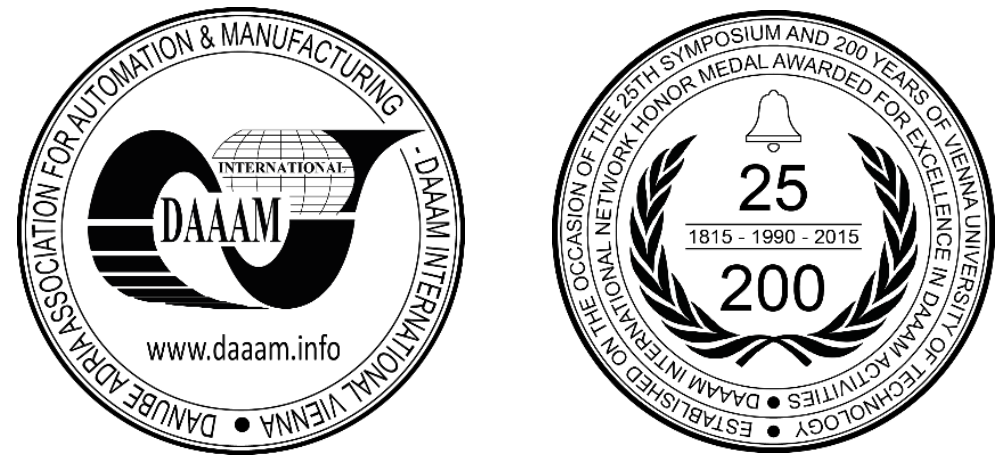

This Publication has to be referred as: Baicu, A[ndrei] V[alentin] (2017). Methods of Assessment and Training of a Company Towards the Enterprise 4.0, Proceedings of the 28th DAAAM International Symposium, pp.1065-1073, B. Katalinic (Ed.), Published by DAAAM International, ISBN 978-3-902734-11-2, ISSN 1726-9679, Vienna, Austria DOI: $10.2507 / 28$ th.daaam.proceedings. 148

\begin{abstract}
This paper is about identifying an enterprise's analysis and evaluation tool, starting from the general characteristics of an organization and initial testing on two companies: a real company that has recently gone through a process of change and a theoretical enterprise type 4.0 .

Finding an analytical tool leads to a method of working with this tool. Analysing a company allows us to identify vulnerabilities and imbalances. The method proposed by this paper consists in analysing the enterprise based on an instrument that determines the balance of the complementary factors that describe the enterprise. These complementary factors and relations of determination are detailed.
\end{abstract}

Keywords: Industry 4.0; Evaluation tool for organization; Complementarity; Complementarity factors; Determinant and determined

\section{Introduction}

Adaptation to the new requirements of the world economy, adaptation of new technologies, automation, led to a new industrial revolution, 4.0. Industry 4.0 turns the entire production cycle of a product from its design to its delivery, increasing production speed by $30 \%$, efficiency by $25 \%$ (according to the Boston Consulting Group) and raising product personalization to previously unseen levels. According to BCG, industry transformation has as sources 9 elements [8].

It is needed to follow a series of steps to move a company to industry 4.0 whose steps are described in BCG [9]. One of them is organization preparation [3]. From the above, some observations are made:

- The proliferation of information systems, automation and interconnection will change the current business system.

- Using machines for analytical purposes, the explosion of information will lead to a new way of understanding systems and organizations. For such a radical change, you need preparation.

The method proposed by this paper consists in analysing the enterprise based on an instrument that determines the balance of the complementary factors that describe the enterprise. These complementary factors are detailed in chapters 2 and 3 of the paper. With the help of the relations of determination - described in chapter 4 - measures for balancing the enterprise with the purpose of its transition to the enterprise are established. 


\section{Complementarity}

Analysing contemporary models of organizations - such as virtual enterprises and learning organizations - we have found that the differences between them are complementary. More precisely, their combined qualities form an ideal model.

As proof of the need to combine the two business models, it is noticed that more and more large companies develop common features with the two types of organizations mentioned above. The possibility of combining features proves that they are complementary, not opposite.

For example, the BEST Awards recognize organizations that demonstrate enterprise-wide success as a result of employee talent development [12]. Looking to the list of winners, we can see that many of the winners have the characteristics of the two types of organization.

One of the organization's permanent issues is getting new capabilities. One of the resources is permanent innovation. In order to be able to analyse these adaptive processes, we must observe the relationship between exploring new possibilities and exploiting the already existing certitudes.

Innovative exploitation generates procedures, methods, solutions or tools that are used in the production or sales processes and that enable the company to gain competitive advantage by increasing customer satisfaction.

Innovative exploration enables the company to position itself properly in the marketplace, find new opportunities and new business solutions, cooperate with partners in other production / service areas that produce new technologies.

Both methods are necessary in the activity of a company; they can support each other or alternate in the good work of a company. It should be remembered that the excessive use of one of the two methods could adversely affect the evolution of the company. It can be considered consider that the two methods are complementary.

Analysing models of organizational structure, we distinguish two representatives:

1. The hierarchy is an organizational structure in which ranks are classified according to the levels of importance. The image of this type of structure of an organization can be represented as a pyramid one.

2. A heterarchy is an organization system in which the elements of the organization are irregular (non-hierarchical) or possess the potential to be classified in several different ways. This system it is named by some authors as a non-hierarchical system [10][11].

The two ways of structuring (hierarchically and heterarchically) are not mutually exclusive, so they are complementary, and they can be found at departmental level within the same company. We have noticed that a company's model, the methods used by it and the structure can be analysed in terms of two complementary elements. Obviously, an organization cannot manifest only one of the complementary factors.

The question is whether we can build an analysis tool based on the complementarity of some organizational factors that can help us evaluate the company's status and provide clues about what the business should do in the future.

In order to be able to make this assessment, we need to find the right indicators that describe the organization and which we will call complementarity factors. The factors give us quantitative information about characteristics considered representative of an organization.

$\begin{array}{lll}\text { E.g.: } & \text { Element: } & \text { Organizational Structure } \\ & \text { Feature: } & \text { Degree of formalization } \\ & \text { Complementarity factors: } & \text { Verticality - horizontality. }\end{array}$

The analysis of the organization cannot be done solely on the basis of finding the complementarity factors and their individual evaluation. Only together with the sum of all complementarity factors and their assessment they can provide us with information about the balance of the organization.

For evaluation, each complementarity factor will be given a score of 1 to 5, even if an organization can be described as missing one of the two complementary factors. I think that in fact, the second factor also manifests itself in some way within the organization so we will give at least one point.

The factors chosen in this work will be described and explained in the next chapter without claiming that they are the only ones. I have, however, sought the simplest approach of the study.

In the table below we included the most common elements and features founded in management textbooks and organization theory [2][4][10].I followed particularly those written by S. P. Robbins [5].

The complementary factors are entered in columns 3 and 4 as follows:

- Centric complementary factors are characterized by firm, strong, well-rounded, inward-facing features.

- Centrifugal complementary factors are distinguished by flexibility, low contour, horizontality, orientation towards the outside. 


\begin{tabular}{|c|c|c|c|}
\hline $\begin{array}{c}\text { Elements of the } \\
\text { organization }\end{array}$ & Characteristics & $\begin{array}{c}\text { Complementary factor } \\
\text { centripetal }\end{array}$ & $\begin{array}{c}\text { Complementary factor } \\
\text { centrifugal }\end{array}$ \\
\hline Structure & 1. Complexity & Vertical diferentiation & Orizontal diferentiation \\
\hline & 2. Formalization & Clearly defined & Permanent adaptable \\
\hline & 3. Centralization & Concentrated & Dispersed \\
\hline Design & & Functional & Divisional \\
\hline Management & & Omnipotent & Symbolic/Democratic \\
\hline Culture & & Existent & External \\
\hline Proceses & 1. Changing processes & Internal & Informal \\
\hline & 2. Recruitment & Internal & Renewal \\
\hline & 3. Learning & Formal & Different \\
\hline Strategies & 1. Corporate & Growing & Informal \\
\hline
\end{tabular}

Table 1. Descriptive complementary factors of an organization

If the total point in column 3 is equal to the total in column 4, we consider that we have a balanced organization. The score of the two columns gives us a representation of the company's "health condition". If the sum in column 3 is very different from column 4 , we need to analyse where the maximum points of differentiation are and what is their significance.

The economic indicators, balance sheets, on-going contracts give us a snapshot of the situation of a company. Based on these, some forecasts may also be made over certain periods of time.

\section{Complementarity factors}

As the organization is an open system, the state of equilibrium is given by the result of permanent actions to and from the system on one hand, and by the internal balance of the system on the other. With complementarity factors, we seek to analyse this internal balance. These factors must present the qualities of the system at the structural level; the balance between them is representing the balance of the system.

To determine which complementarity factors can describe the status of an organization, we need to look at the elements that describe an organization in general.

The elements of an organization have several features. We will seek to attribute each of them two complementary factors. We have chosen the most common features in management textbooks and organization theory [6] [7].

What elements can we meet in an organization and which are the appropriate complementarity factors? The identified elements are: structure, design, management, organizational culture, processes, strategies and relationships between the members of the organization.

\subsection{Organization Structure}

The structure of the organization defines how the tasks are assigned, who reports to whom, what are the formal coordination mechanisms, and the patterns of interaction that will be followed.

The organizational structure has three components [5]:
1. Complexity
2. Formalization
3. Centralization

"Complexity refers to the degree of differentiation that exists within an organization.

In this situation, vertical differentiation and horizontal differentiation can be considered complementary factors that determine the complexity of the organization.

Formalization refers to the degree to which workplaces and procedures within the organization are standardized. If a job is very formal, those who carry out their work have a minimum freedom in what needs to be done, when it should be done and how to do it. From this point of view we can consider that we have two complementary factors describing formalization: clearly defined and permanently adaptable.

"Centralization is the most difficult definition of the three components. Most organizational theorists agree that the term refers to the degree to which the decision-making process is concentrated in a single point of the organization." - P. Robbins.

For the description of centralization we have two complementary factors: Concentrated and dispersed. 


\subsection{Design of Enterprises}

Robbins and Coulter describes three traditional business design patterns [5].

- The simple structure is an organizational structure with poor divisions across departments, the authority being centralized to one person. It is typical of an organization with a small number of people.

- Functional structure is the organizational design that makes clustering of specialties based on similarity or association. The structure can be viewed as a split of functional departments across the organization.

- The divisional structure is that organizational structure made up of separate business units. In this type of structure, each department has limited autonomy and a manager responsible for its performance.

In the literature, we also encounter the matrix structure, a structure that represents practically the combination of the divisional structure and the functional one. Given that when an enterprise grows any simple structure, it becomes a functional or divisional structure, to describe the enterprise design, we have chosen two complementary factors: Functional and Divisional.

\subsection{Management}

Managerial competence has constraints from the organizational environment and organizational culture. According to S. P. Robbins, there are two perspectives in management theory [5].

- The omnipotent vision of leadership: managers are directly responsible for the success or failure of an organization.

- $\quad$ The symbolic vision of leadership: much of the success or failure of an organization is given by external forces controlled by managers. The complementary factors are: omnipotent and symbolic.

\subsection{Organizational Culture}

Organizational culture is another element that we encounter within an organization and can have a significant influence on its results. M. Armstrong summarized the most common classifications of Roger Harrison, Charles Handy and Edgar Schein. Most of the time, there are 4 dimensions [1]. To simplify and reach only 2 elements that can represent the two complementarity factors, we have made the following classification:

- Culture based on own members (can be a culture of power), on the existing procedures or competencies of the members of the organization.

- The culture of the results - is based on the expected results (culture of achievements) or on the personal motivation (can therefore be a culture of support).

The two complementary factors are represented by what they have/existent and what they want/ wanted.

\subsection{Processes}

\section{The process of change}

Changes in the company may be determined by internal or external factors. The internal ones refer to a new organizational strategy, changing the composition of the workforce, new equipment, or changing the attitude of the employees. External changes mean changing consumer needs and wishes, new governmental laws, new technologies, or economic changes.

The two complementary factors are internal change and external change.

\section{Recruitment}

The two complementarity factors are internal and external recruitment.

\section{Employee training}

Employee training can be done informally or formally [10]. The informal learning is done permanently; the skills development takes place based on feedback from the workplace. Formal learning is planned, systematically and requires structured training and programs that contain training and practice.

The complementarity factors that define the training are formal and informal learning.

\subsection{Strategies}

According to S. P. Robbins there are three types of strategies: corporate, competitive and functional [5]. To identify the complementary factors, we considered the first two types because functional strategy belongs to managers in lower levels. It is the corporate strategy that determines where the business is or where it will be. There are 3 main types of corporate strategy: growth, stability and renewal.

Considering that the strategy which promotes stability, actual preserves what exists, it does not seem relevant to our study, so we have selected the two complementarity factors as: growth and renewal.

The competitive strategy determines how the company will behave in relation to its competitors. We can talk about a lower price strategy or a better product at the same price or the strategy of differentiation - when your product is different through its qualities. The complementarity factors that define the competitive strategy will be better or different. 


\subsection{Relations between members}

Relationships between employees may be formal, established by rules, procedures, protocols, their degree of complexity being directly related to the size of the organization, or may be informal, outside the rules and procedures, of a more personal nature. The two factors that describe relationships between employees are: formal and informal relationships.

\section{Determinant and determined}

Practically, an organization can be described by analysing the structure and design, management, strategy, processes, organizational culture, and relationships among its members. A better understanding of the organization can be achieved through a representation of its elements and the determinations between the elements. For a simplified representation, we will consider the structure and design of the organization as one element - just as they are in some places, as well as the organizational culture and the relationships between its members.

Analysing the elements in the fig.1, establishing the determinations between the elements - who determines and who are determined, we can make an image of the organization that can be represented as follows:

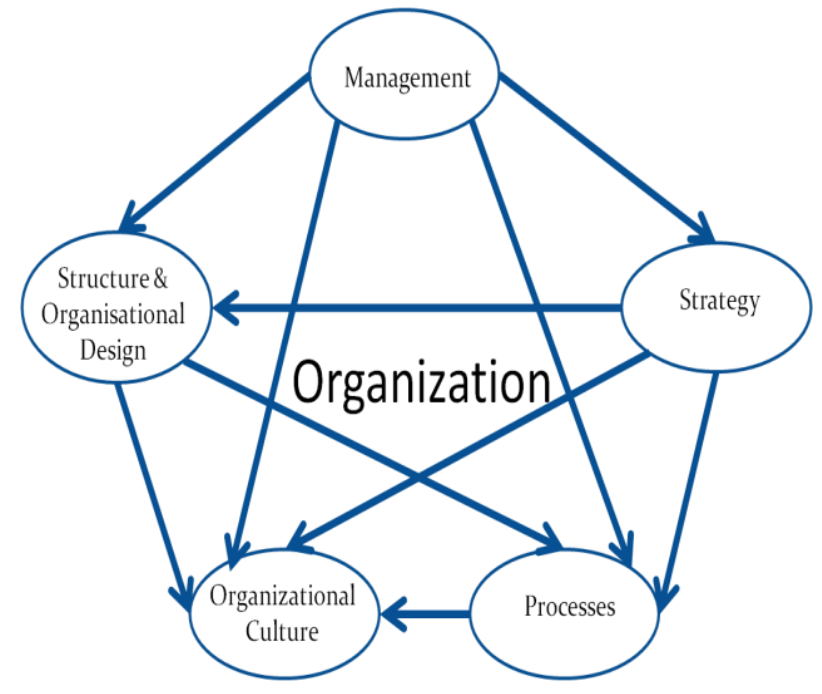

Fig. 1. Representation of an organization through the elements determined and determinant

If we find an imbalance of an element, we can predict which would be the next element affected. At the same time we can find out if the unbalanced is the result of the element that determines the unbalanced element and this will help to identify the remedial solutions. If we put together the structure and design of the organization with the strategy, being determined by management and determining the same elements (processes, culture and organizational relationships) and introducing the results of the organization as a determinant for its management, the result is the following scheme:

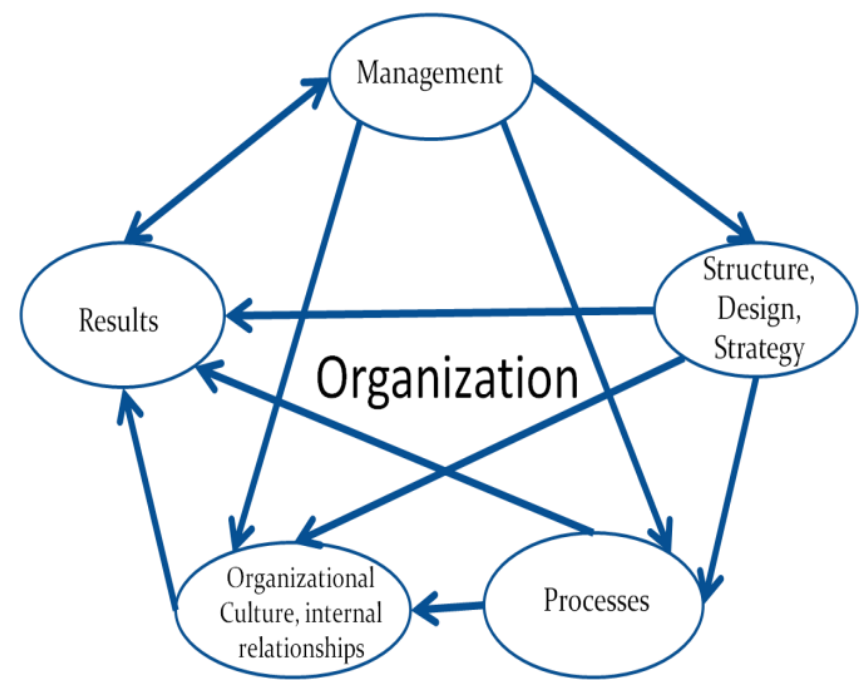

Fig. 2. Representation of an organization by including the results in the elements determined and determinant. 
People who are part of the organization create organizational culture and relationships between members. Practically, the element in our schemes represents the members of the organization. Structure, organization design, and strategy are the result of thinking and planning made by the management. Processes are the action, the concrete activities, the work itself.

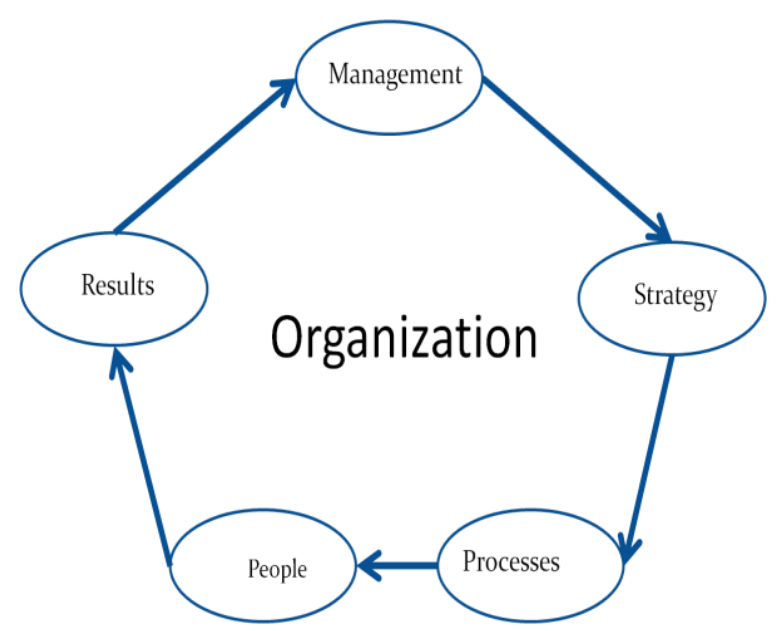

Fig. 3. Representation of a company by redefined elements

Redrawing the above scheme, by redefining the elements, we get figure 3 . In this determination cycle, the ultimate goal of the enterprise is to achieve results. Higher performance results are conditioned by innovation and permanent adaptation. Under the conditions of the Fourth Industrial Revolution, exploitation innovation can be largely taken over by cars, computers and the Internet, all of which resolve many of the structures, strategies and processes, continuously improving them. What about innovative exploration? It is dependent on the human factor and will remain as it is at least until the moment of the development of an artificial intelligence superior to the one existing today.

\subsection{Case Study - The application of the assessment tool on a real business}

\begin{tabular}{|c|c|c|c|}
\hline $\begin{array}{c}\text { Elements of the } \\
\text { organization }\end{array}$ & Characteristics & $\begin{array}{c}\text { Complementary factor } \\
\text { centripetal }\end{array}$ & $\begin{array}{c}\text { Complementary factor } \\
\text { centrifugal }\end{array}$ \\
\hline \multirow[t]{6}{*}{ Structure } & Complexity & Vertical diferentiation & Orizontal diferentiation \\
\hline & & 1 & 2 \\
\hline & Formalization & Clearly defined & Permanent adaptable \\
\hline & & 1 & 4 \\
\hline & Centralization & Concentrated & Dispersed \\
\hline & & 5 & 2 \\
\hline \multirow[t]{2}{*}{ Design } & & Functional & Divizional \\
\hline & & 5 & 1 \\
\hline \multirow[t]{2}{*}{ Management } & & Omnipotent & Simbolic \\
\hline & & 5 & 1 \\
\hline \multirow[t]{2}{*}{ Culture } & & Existent & Wanted \\
\hline & & 3 & 2 \\
\hline \multirow[t]{6}{*}{ Processess } & Changing processess & Internal & External \\
\hline & & 1 & 1 \\
\hline & Recruitment & Internal & External \\
\hline & & 2 & 5 \\
\hline & Learning & Formal & Informal \\
\hline & & 1 & 1 \\
\hline \multirow[t]{4}{*}{ Strategies } & Corporate strategy & Growing & Renewal \\
\hline & & 2 & 1 \\
\hline & Competitive strategy & Better & Different \\
\hline & & 5 & 5 \\
\hline \multirow[t]{2}{*}{ Employees Relationships } & & Formal & Informal \\
\hline & & 5 & 5 \\
\hline Total & & 36 & 30 \\
\hline
\end{tabular}

Table 2. The situation of a company in October 2016 evaluated through the complementarity factors 
The study was done for a company in France, a subsidiary of the multinational company that has subsidiaries in the United States, Europe, China, Russia, India, and South Africa. The company had good results, in accordance with the forecasts. The company has between 50 and 100 employees. The field of activity is animal genetics. The information has been supplied in the framework of an interview with the regional director of human resources, responsible for France, Italy, Germany and Poland. On the basis of the information received we have evaluated and summarized the situation of the company in October 2016 and July 2017. By analysing the table 2 we find that there is a significant difference between the two complementary groups $(16.7 \%)$ that indicates a possible imbalance. We find that the biggest differences come from management and structural design (4 points). Other differences we encounter in the structure of the organization, the degree of complexity, the degree of centralization and the recruitment process.

According to the principle stated above, for optimum results, a company should have the complementary factors in equilibrium and should reduce the differences through organizational changes applied in areas where the differences are greatest. This means that changes at management level, organizational design, structure and processes should be made.

In an absolutely unexpected way in November 2016, the general manager decides to leave and it is appointed a new general manager and a new human resources manager from within the global organization but from different countries.

They find that there are some procedural problems, imbalances in the structure and a high level of dissatisfaction among employees due to the failure to keep the promises made by the former manager. The new manager implements a series of changes with medium and short-term impact. In July 2017, the company's situation is described by those in the company according to the table below.

By implementing relatively simple changes, there is a decrease in the difference between the two groups of complementary factors to $11.2 \%$ within a few months. We have a single 4 point difference in organizational design - this can not be changed dramatically due to the small size of the company and we still have a 3 point difference in the recruitment process that is mainly external due to the small size of the company on one hand and the fact that the company it is growing, on the other hand. The management gap also dropped to three points due to the implemented changes: an additional level of management has been added, the number of individual trainings increased, the degree of delegation increased, few processes have been changed and a process of changing the employment contracts begins.

\subsection{Results and Interpretation}

The biggest imbalance has been found in October 2016 exactly where the first change appear through the resignation of the general manager. Scoring changes were noted between the two tables, generally where the differences were large in the first table (representing the initial diagnosis of company performance.) This shows that the imbalances of the initial situation are found in the weaknesses identified using the proposed analysis tool here.

\begin{tabular}{|c|c|c|c|}
\hline $\begin{array}{c}\text { Elements of the } \\
\text { organization }\end{array}$ & Characteristics & $\begin{array}{c}\text { Complementary factor } \\
\text { centripetal }\end{array}$ & $\begin{array}{c}\text { Complementary factor } \\
\text { centrifugal }\end{array}$ \\
\hline \multirow[t]{6}{*}{ Structure } & Complexity & Vertical diferentiation & Orizontal diferentiation \\
\hline & & 2 & 2 \\
\hline & Formalization & Clearly defined & Permanent adaptable \\
\hline & & 2 & 4 \\
\hline & Centralizatiom & Concentrated & Dispersed \\
\hline & & 3 & 3 \\
\hline \multirow[t]{2}{*}{ Design } & & Functional & Divisional \\
\hline & & 5 & 1 \\
\hline \multirow[t]{2}{*}{ Management } & & Omnipotent & Simbolic \\
\hline & & 4 & 1 \\
\hline \multirow[t]{2}{*}{ Culture } & & Existent & Wanted \\
\hline & & 4 & 3 \\
\hline \multirow{6}{*}{ Procese } & Changing processess & Internal & External \\
\hline & & 2 & 1 \\
\hline & Recruitment & Internal & External \\
\hline & & 2 & 5 \\
\hline & Learning & Formal & Informal \\
\hline & & 3 & 3 \\
\hline \multirow[t]{4}{*}{ Strategies } & Corporate strategy & Growing & Renewal \\
\hline & & 3 & 2 \\
\hline & Competitive strategy & Better & Different \\
\hline & & 1 & 1 \\
\hline \multirow[t]{2}{*}{ Employees Relationships } & & Formal & Informal \\
\hline & & 4 & 5 \\
\hline Total & & 35 & 31 \\
\hline
\end{tabular}

Table 3. The Company as described in July 2017 
Imbalances or malfunctions could not be found by analysing the classical economic indicators. By strict reporting to them, the company's results were good. However, following global questionnaires made in 2013 and 2015, there may be some misunderstandings and discontents of the company's employees in France in 2015.

A very good correlation between the performance of the company as a result of changes made by the new management and the evolution of the complementarity factors in Table 3 was found. This concordance validates the analysis of complementarity factors as a pertinent diagnosis of a company's health and also the ability to suggest actions that can be taken to maximize the performance of the organization. It is possible to estimate the consequences of existing imbalances and propose solutions to remedy them.

The company is interested to progress toward the model 4.0 and will start with small steps by implementing first a proper ERP system. However before talking about the 4.0 version of this company, the management need to solve the current problems and this is facilitated by the usage of this instrument. The transition to 4.0 implies significant changes in current processes, and this will have to be forced by the external environment or the need to become more competitive.

\section{Enterprise analysis 4.0 based on the evaluation tool}

\subsection{Simulation - The application of the assessment tool on a theoretical 4.0 enterprise}

Doing a simulation for a 4.0 enterprise by using the complementarity factors, we will give a maximum score (5 points) to the complementary factor that is likely to be representative for a 4.0 enterprise and a minimum score ( 1 point) for the complementary factor that is unlikely to be representative or even defining the enterprise at all. The results are presented in table 4.

\begin{tabular}{|c|c|c|c|}
\hline $\begin{array}{c}\text { Elements of the } \\
\text { organization }\end{array}$ & Characteristics & $\begin{array}{c}\text { Complementary factor } \\
\text { centripetal }\end{array}$ & $\begin{array}{c}\text { Complementary factor } \\
\text { centrifugal }\end{array}$ \\
\hline Structure & Complexity & Vertical diferentiation & Orizontal diferentiation \\
\hline & Formalization & Clearly defined & Permanent adaptable \\
\hline & Centralizatiom & Concentrated & Dispersed \\
\hline & & 5 & 5 \\
\hline & & Functional & Divisional \\
\hline & & 5 & Simbolic \\
\hline Design & & Omnipotent & 5 \\
\hline Management & & 5 & Wanted \\
\hline Culture & & Existent & 5 \\
\hline Procese & & 5 & External \\
\hline & Changing processess & Internal & 1 \\
\hline & & 1 & External \\
\hline & Recruitment & Internal & 1 \\
\hline & & 5 & Informal \\
\hline & Learning & Formal & 1 \\
\hline & & 5 & Renewal \\
\hline & & Growing & 5 \\
\hline & & 5 & Better \\
\hline
\end{tabular}

Table 4. Enterprise 4.0 evaluated with the assessment tool presented previously

\subsection{Interpretation}

By doing detailed analysis, we notice that the differences between the complementary factors occur in the recruitment, training, competitive strategy and employee relations.

Considering the degree of complexity of specialization in the Enterprise 4.0, internal recruitment becomes a priority compare with the external recruitment. External recruitment brings, besides the new skills required by the job description, experiences from outside the system and new knowledge. Permanent recruitment from inside leads to recurrence and systematic errors.

Continuous automatization of processes determines the prioritization of formal training, standardization. Thus, the role of informal learning becomes smaller.

The competitive strategy for Enterprise 4.0 is based on sustained efficiency, continuous improvement of products and services, so the complementary factor of the 'better' competition strategy prevails over the 'different' one. 
Email use, teleconferencing will reduce informal relationships, and the stimulation induced by direct contact between people tends to disappear.

It appears that there is a risk of diminishing creativity at the organization level, entering a recurrence that can cause problems for the organization. Competition can also appeal to the same technological solutions with similar results. Differentiation will be crucial in this case. An important element is the creative element, which is weakened by diminishing external recruitment, informal training and informal relationships among employees.

\section{Conclusion}

Although the instrument defined here is new and has been tested on one real enterprise, the results are encouraging and the recipient's feedback very good. Simulation on the model of an enterprise 4.0 has led to results and conclusions that outline the actions needed in such a company to achieve a good level of indicators of long-term performance. Both the analysis tool created and the schemes that show us the determinants and determinations can show the general situation in an enterprise. The diagnostic tool outlined in this paper aims to assist managerial decisions in this critical area for the company's long-term performance. It needs a refinement to highlight the problems that exist in a company. This can only be done by analysing several companies having different organizational cultures to obtain a general formula for application. These results are the premises of refining this tool by testing it on a larger number of interested companies.

\section{References}

[1] Armstrong, M; Taylor, S. (2006). Human Resource Management Practice, Kogan Page, ISBN 9780749469641, London, England

[2] Coteț, C. E.; Coteț, C. E. (2014). Managementul Resurselor Umane în Ingineria Industrială-Human Resources Management in Industrial Engineering, Printech, ISBN 978-606-23-0320-4,Bucharest, Romania

[3] Lorenz, M.; Rüßmann, M. \& Strack, R. (2016) . Man and Machine in Industry 4.0, Boston Consulting Group, Available from: https://www.bcg.com Accessed: 2016-10-10

[4] McAuley, J.; Duberley, J. \& Johnson, P. (2007). Organization Theory-Challenge and Perspectives, Pearson, ISBN 10: 0-273-68774-3,Harlow, England

[5] Robbins, S. P.; Coulter, M. (2012). Management, Pearson, ISBN 978-0-216384-2, Boston

[6] Robbins, S. P.; Judge, T. A. (2015). Essentials of Organizational Behavior, Pearson,ISBN:10 1292090073, Harlow England

[7] Robbins, S. P.; Judge, T. A. (2013). Organizational Behaviour, Pearson, ISBN 10: 0-13-283487-1, Boston

[8] Rüßmann, M.; Lorenz, M. \& Gerbert, P. (2015). Industry 4.0 The future of Productivity and Growth in Manufacturing, Boston Consulting Group, Available from: https://www.bcg.com Accessed: 2016-10-10

[9] Sirkin, H. L.; Zinser, M. \& Rose, J.R. (2015) - The Robotics Revolution- Next Great Leap in Manufacturing, Boston Consulting Group, Available from: https://www.bcg.com Accessed: 2016-10-10

[10] Teich, T.; Junghans, S. Kretz, D. \& Trommer, M. (2016). Non-Hierarchical Services Networks, Steered by Competence Cells, Chapter 10 in DAAAM International Scientific Book 2016, pp.103-112, B. Katalinic (Ed.), Published by DAAAM International, ISBN 978-3- 902734-09-9, ISSN 1726-9687, Vienna, Austria

[11] Thietart, R.A. (2017) Le management-Management, Presses Universitaires de France, ISBN 9782130794721, Paris

[12] https://events.td.org/Events/ATD-Best/Winners, (2017). 2017 BEST Awards Winners, Accessed on: 2017-06-02 